Research Paper:

\title{
Epidemiology of Spine Trauma and Spinal Cord Injuries in the North of Iran
}

\author{
Sasan Andalib ${ }^{1,2,3}$, Zahra Mohtasham-Amiri ${ }^{1}$, Shahrokh Yousefzadeh-Chabok ${ }^{1,2,3^{*}}$, Alia Saberi ${ }^{*}$, Zoheir Reihanian ${ }^{1,3}$, Leila Kouchakine- \\ jad-Eramsadati ${ }^{1}$, Sara Sayad-Fathi ${ }^{2}$ Q , Hadiseh Shokat $^{1}{ }^{9}$, Bahador Hasanzadeh ${ }^{1}$, Samaneh Ghorbani-Shirkouhi ${ }^{2}$
}

1. Guilan Road Trauma Research Center, Poursina Hospital, School of Medicine, Guilan University of Medical Sciences, Rasht, Iran

2. Neuroscience Research Center, Poursina Hospital, School of Medicine, Guilan University of Medical Sciences, Rasht, Iran

3. Department of Neurosurgery, Poursina Hospital, School of Medicine, Guilan University of Medical Sciences, Rasht, Iran

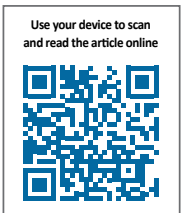

ditation: Andalib S, Mohtasham-Amiri Z, Yousefzadeh-Chabok Sh, Saberi A, Reihanian Z, Kouchakinejad-Eramsadati L, et al. Epidemiology of Spine Trauma and Spinal Cord Injuries in the North of Iran. Iran J Neurosurg. 2018; 4(4):199-204. http://dx.doi. org/10.32598/irjns.4.4.180

http://dx.doi.org/10.32598/irjns.4.4.180

Article info:

Received: 07 Apr 2018

Accepted: 03 Jul 2018

Available Online: 01 October 2018

Keywords:

Spinal cord injury, Spine,

Trauma, Neurological defect

\begin{abstract}
Background and Aim: Traumatic Spinal Cord Injury (SCI) is one of the most traumatic events threatening patients' well-being and places a financial burden on health care system. The first step in determination of the exact impact of $\mathrm{SCl}$ is to estimate the pattern of traumatic injuries in a population and also the type of frequently occurred co-injuries. Hence, this study was conducted to assess the frequency of anatomy, type of spine injuries, and associated co-injuries in patients with trauma in Poursina Hospital of Guilan province in Iran.
\end{abstract}

Methods and Materials/Patients: A descriptive cross-sectional study was carried out on traumatic spine patients admitted to the Poursina hospital of Rasht, a referral therapeutic center for trauma in north of Iran, in Rasht during 2015 to 2019. Data were extracted from the SCl registry of Poursina Hospital, Rasht, Guilan, Iran.

Results: A total of 274 records were reviewed. Seventy-six patients were females and 198 patients were males. Mean $\pm S D$ of age of the patients was $42.27 \pm 16.83$ years. Based on this survey, most of the patients (43.8\%) had SCl in lumbar region. Locked facet was seen in 12 patients. Fifty-seven patients (20.8\%) complained about having pain. The median of VAS score was 6 (range=6). Coexistence of associated injuries (e.g. limb fractures, TBI, Internal bleeding, etc.) was found in $27.4 \%$ of the patients. According to ASIA (The American Spinal Injury Association) impairment scale, three patients $(2.9 \%)$ had score $A$, and 100 patients $(97.1 \%)$ had score E neurological defects.

Conclusion: The most telling reiteration to be drawn is that men mostly suffered from spine trauma. Lumbar region was the most susceptible location of SCl. Moreover, most of the patients experienced score $\mathrm{E}$ (normal neurological charcteristics) according to ASIA.

\section{* Corresponding Author:}

Shahrokh Yousefzadeh-Chabok, MD.

Address: Guilan Road Trauma Research Center, Poursina Hospital, School of Medicine, Guilan University of Medical Sciences, Rasht, Iran Tel: +98 (13) 33311472

E-mail: neurosurgery97@yahoo.com

\section{* Corresponding Author:}

Alia Saberi, $M D$.

Address: Neuroscience Research Center, Poursina Hospital, School of Medicine, Guilan University of Medical Sciences, Rasht, Iran Tel: +98 (911) 1302487

E-mail: alia.saberi1@yahoo.com 


\section{Highlights}

- Men mostly suffered from spine trauma, compared with women.

- Lumbar region was the most susceptible location of spinal cord injury.

- Most of the patients had score E neurological defects according to the American Spinal Injury Association.

\section{Plain Language Summary}

Traumatic Spinal Cord Injury ( $\mathrm{SCl}$ ) is one of the most traumatic events threatening patients' health and causes a financial burden on the health care system. The first step in determination of the exact impact of $\mathrm{SCl}$ is to estimate the pattern of traumatic injuries in a population as well as the type of frequently occurred co-injuries. In this regard, this study was conducted to assess the frequency of anatomy, type of spine injuries, and associated co-injuries in patients with traumatic SCl in Poursina Hospital of Rasht, Iran during 2015 to 2019. Data were extracted from the $\mathrm{SCl}$ registry of the Hospital. A total of 274 records were reviewed. Seventy-six patients were females and 198 patients were males. The mean age of patients was 42.27 years. Based on this survey, most of the patients $(43.8 \%)$ had $\mathrm{SCl}$ in lumbar region, and 47 patients $(20.8 \%)$ complained about having pain. Coexistence of associated injuries (e.g. limb fractures, traumatic brain injury, internal bleeding, etc.) was found in $27.4 \%$ of the patients. Men mostly suffered from spine trauma. Lumbar region was the most susceptible location of $\mathrm{SCl}$. Moreover, most of the patients experienced normal neurological characteristics according to the American Spinal Injury Association.

\section{Introduction}

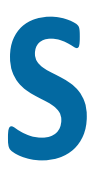

pinal Cord Injury (SCI) is defined as a direct damage to the spinal cord, causing temporary or permanent damage to its performance. $\mathrm{SCl}$ can be divided into two main categories: traumatic and non-traumatic [1,

2]. Traumatic $\mathrm{SCl}$ occurs due to automobile crash, falling down, sports, etc., while the non-traumatic $\mathrm{SCl}$ is secondary to other complications, as tumors, infections, and degenerative disc disease. Chronologically, patients with $\mathrm{SCl}$ form four subgroups: i) acute phase patients; who got injured within last 48 hours, ii) subacute phase patients; who got injured between 48 hours to 14 days ago, iii) intermediate phase patients; who got injured between 14 days to 6 months ago, and iv) chronic phase patients; who injury occurred to them 6 months ago and earlier. $\mathrm{SCl}$ includes two steps. Primary injury arises from a mechanical force to the nervous tissue resulting in direct damage and a secondary insult which deteriorates the condition [3].

Neuron and glial cell deaths occur directly following $\mathrm{SCl}$, or as a result of the liked ischemia and infection. These changes and associated glial scar compromise internal architecture of the spinal cord, and accompanying with the slow rate of axonal regeneration and remyelination, are factors determining the weak potential of spinal cord for self-regeneration
[4]. Hence, it can be expected that regardless of the injury mechanism, $\mathrm{SCl}$ is almost always associated with permanent neurological damage.

The cost of care of a patient bearing $\mathrm{SCl}$ is estimated to be approximately 1.1 to 6.4 million dollars during his/her lifetime, highlighting the necessity of placing the prevention before the treatment. It has been reported that men have a higher chance (79.8\%) to suffer from $\mathrm{SCl}$, compared with women (20.9\%) [5] and the risk for morbidity and mortality is higher when the site of the injury is close to the head. Traumatic SCl occurs mostly in the cervical spinal cord (60\%) and the risk for its occurrence in thoracic and lumbosacral spinal cord is rather low (32\% and 6\%, respectively) [5].

Elderly, multi-system trauma, and accident severity are other factors correlated with morbidity and mortality [6, 7]. Although today with advances that have been made in medical sciences the survival rate in $\mathrm{SCl}$ patients seems to be promising, these patients still experience a shorter lifespan when compared to age-matched healthy individuals [8]. During hospital stay, the mortality rate in $\mathrm{SCl}$ patients has been estimated to be $4-14 \%$. After being discharged, the mortality rate for the patients was estimated to be $3.8 \%$ in the first year and $1.6 \%$ in the second year following the accident [9]. 
Depending on the mechanism and type of the injury, traumatic damage to the spine can cause $\mathrm{SCl}$ at cervical, thoracic, or lumbosacral spinal levels in spinal cord, which are almost always detectable by one of the medical imaging techniques. $\mathrm{SCl}$ includes fractures, tensions, dislocations, etc., which most of the times are accompanied by Traumatic Brain Injury (TBI), burning, fractures of the limbs, and internal organs damage. Damage to the spinal cord could result in complete or incomplete $\mathrm{SCl}$ in different levels. International standards for neurological classification of spinal cord injuries, mostly referred to as the ASIA Impairment Scale (AIS), is a scale classifying spinal cord injuries according to motor and sensory functions and the severity of the injury [10].

Regarding the physical, mental, emotional, social, and economic impacts on the patient, her/his family, and the health system, it is necessary to put prevention as the first line treatment for $\mathrm{SCl}$. But in some cases that it is impossible to prevent the injury, providing efficient health care in the shortest possible time frame is of the utmost importance as it turned out to be correlated with successful outcome [9].

The differences in culture and climate and also urban texture can have a direct impact on the incidence of $\mathrm{SCl}$ and even their types and levels. Due to the existence of various gardens and building sites, the risk of falling down is high in Guilan province. Additionally, its mild climate attracts passengers from all over the country in holidays such as Nowrouz and summer holidays, making it a province with a somehow custom-built traffic pattern with increased risk of car accidents. There are studies on the traumatic $\mathrm{SCl}$ in Guilan province, but either their focuses are on the regions of the spinal cord involved in the injury or they are assessing results in a short period of time. Thus, this study was aimed to investigate not only the anatomical site of the $\mathrm{SCls}$, but also the types and levels of these injuries and the associated injuries in patients admitted to the Guilan trauma center.

\section{Methods \& Materials/ Patients}

\section{Study design}

The present cross-sectional study was based on a survey carried out on patients with spine trauma admitted to the Poursina hospital trauma center in Rasht and registered to Guilan trauma center spinal cord injuries' registry during 2015 to 2019. Medical records of patients with confirmed CT-scan and/or MRI signs of SCl were enrolled in the study. Demographic information including age, sex, anatomical site of the injury, type of the injury, type of the injury to the C1C2 vertebrae, type of the associated injuries, presence of locked facet, and neurological defects ASIA (The American
Spinal Injury Association) impairment scale [10] were extracted from the registry.

\section{Statistical analyses}

Absolute and relative percentage abundance of the variables were calculated via SPSS statistical software V. 22 (IBM Corp, Armonk, NY, USA).

\section{Results}

A total of 274 medical records of patients were reviewed. Seventy-six patients were females $(27.7 \%)$ and 198 patients were males (72.3\%). The Mean \pm SD of patients' age was $42.27 \pm 16.83$ years. All patients had nonpenetrating traumatic injuries. Based on this survey, 120 patients (43.8\%) suffered from $\mathrm{SCl}$ in lumbar region of the spinal cord, 76 patients $(27.7 \%)$ had cervical $\mathrm{SCl}$, and 50 patients $(18.2 \%)$ had thoracic $\mathrm{SCl}$. Also, 14 patients (5.1\%) were reported with both thoracic and lumbar injuries, 10 patients (3.6\%) with both thoracic and cervical injuries, 1 patient $(0.4 \%)$ with both lumbar and sacral injuries, 2 patients $(0.7 \%)$ with both lumbar and cervical injuries, and 1 patient $(0.4 \%)$ with cervical and thoracic and lumbar injuries. Tables 1, 2, and 3 represent a summary on the type of fractures and/or displacements in the cervical, thoracic and lumbar regions of the spine, respectively. Locked facet was reported in 12 patients (4.4\%).

Accompanying injuries was reported in 75 patients (27.4\%) of which 55 patients $(73.3 \%$ ) had limb fractures, 11 patients $(14.7 \%)$ had TBI, 4 patients (5.3\%) represented with internal bleeding, and 5 patients (6.7\%) suffered from both TBI and limb fractures. Fifty-seven patients (20.8\%) complained about having pain. Table 4 summarizes Visual Analogue Scores (VAS score) [11], assessed in conscious patients who had accompanying injuries, as well as spine trauma. The median of VAS score was 6 (range=6). Of the 103 patients with $\mathrm{SCl}$, according to ASIA impairment scale, 3 patients $(2.9 \%)$ had score $A$, and 100 patients (97.1\%) had score E neurological defects. Twenty-eight patients (10.2\%) were not able to control their urine and 24 of them (8.8\%) had no control over excretion.

\section{Discussion}

In the present study, most of the patients showed normal neurological characteristics (E) according to ASIA. Locked facet was not a frequently observed event in the patients with spine trauma. Limb fracture was the most important associated disease in these patients, in contrast to pain. Safaei et al. studied 174 patients with 
Table 1. Types of injuries in the cervical region of the spinal cord

\begin{tabular}{ccc}
\hline Types of the Injuries & Frequency & Percentage \\
\hline A0-no bony or minor injuries & 17 & 25.4 \\
A1-compression fracture & 7 & 10.4 \\
A2-coronal Split or pincer fractures & 3 & 4.5 \\
A3-burst fracture & 3 & 4.5 \\
A4-burst fracture or sagittal split injury & 6 & 9.0 \\
C-translational injury & 13 & 19.4 \\
F1-nondisplaced facet fracture & 2 & 3.0 \\
F2-facet fracture with displaced & 4 & 6.0 \\
\hline F4-pathologic subluxation or perched/ dislocated facet & 1 & 1.5 \\
A0-no bony or minor injuries \& A3- burst fracture & 1 & 1.5 \\
A3-burst fracture \& C-translational injury & 2 & 3.0 \\
\hline A0-no bony or minor injuries \& A1-compression fracture & 1 & 1.5 \\
\hline A0-no bony or minor injuries \& A1-compression fracture & 3 & 4.5 \\
\hline C-translational injury \& F1-nondisplaced facet fracture & 1 & 1.5 \\
\hline A4-burst fracture or sagittal split injury \& C-translational injury & 1 & 1.5 \\
\hline A2-coronal split or pincer fractures \& C-translational injury & 1 & 1.5 \\
\hline A2-coronal split or pincer fractures \& C-translational injury & 1 & 1.5 \\
\hline
\end{tabular}

Table 2. Types of injuries involving thoracic region of the spinal cord

\begin{tabular}{ccc}
\hline Type of the Injuries & Frequency & Percentage \\
\hline A0-minor injuries & 7 & 9.3 \\
A1-wedge compression & 16 & 21.3 \\
A2-split & 4 & 5.3 \\
A3-incomplete burst & 17 & 22.7 \\
A4-complete burst & 30 & 40.0 \\
\hline A1-wedge compression \& C-translation/displacement & 1 & 1.3 \\
\hline
\end{tabular}

Table 3. Types of injuries involving lumbar region of the spinal cord

\begin{tabular}{|c|c|c|}
\hline Type of the Injuries & Frequency & Percentage \\
\hline A0-minor injuries & 3 & 2.2 \\
\hline A1-wedge compression & 24 & 17.4 \\
\hline A2-split & 3 & 2.2 \\
\hline A3-incomplete burst & 49 & 35.5 \\
\hline C-translation/displacement & 1 & 0.7 \\
\hline A4-complete burst & 55 & 39.9 \\
\hline B1-monosegmental bony posterior tension band injury / chance fracture & 1 & 0.7 \\
\hline B2-posterior tension band disruption & 1 & 0.7 \\
\hline A3-incomplete burst \& A1-wedge compression & 1 & 0.7 \\
\hline
\end{tabular}


Table 4. VAS Score in patients with traumatic spine injuries

\begin{tabular}{ccc}
\hline VAS Score & Frequency & Percentage \\
\hline Score 2 & 1 & 1.8 \\
Score 3 & 4 & 7.0 \\
Score 4 & 4 & 7.0 \\
\hline Score 5 & 11 & 19.3 \\
Score 6 & 26 & 45.6 \\
Score 7 & 9 & 15.8 \\
Score 8 & 2 & 3.5 \\
\hline & &
\end{tabular}

spine injury in our hospital between 2001 and 2003 and reported that $71.8 \%$ of the patients were male with an average age of $40.75 \pm 15.55$ years [12]. Moreover, lumbar (L1), thoracic (T12), and cervical (C7) spine injuries of spine were found in 54.6, 33.9, and 11.5 percent of the patients with spine injury.

In our study, we observed that 198 patients (72.3\%) were males. The mean of patients' age was 42.27 years. One hundred-twenty patients (43.8\%) suffered from $\mathrm{SCl}$ in lumbar region of the spinal cord, 76 patients $(27.7 \%)$ had cervical $\mathrm{SCl}$, and 50 patients (18.2\%) had thoracic $\mathrm{SCl}$. Furthure, 14 patients (5.1\%) were reported with both thoracic and lumbar injuries, 10 patients (3.6\%) with both thoracic and cervical injuries, 1 patient $(0.4 \%)$ with both lumbar and sacral injuries, 2 patients $(0.7 \%)$ with both lumbar and cervical injuries, and 1 patient $(0.4 \%)$ with cervical and thoracic and lumbar injuries.

In 2015, Yousefzadeh et al. investigated 74 patients with spine injury and found that 88.2 of the patients were male [13]. Moreover, 34 patients (44.7\%) experienced cervical spine injury. Thoracolumbar injuries resulted in $\mathrm{SCl}$ in 23 patients (30.3\%). $29.7 \%$ of the patients had paraplegia and $10.8 \%$ of the patients suffered quadriplegia. Complete $\mathrm{SCl}$ was reported in 25 patients (38.5\%).

In our study, of the 103 patients with $\mathrm{SCl}$, according to ASIA impairment scale, 3 patients (2.9\%) had score A, and 100 patients (97.1\%) had score $E$ neurological defects. Ramezani et al. [14] carried out a cross-sectional investigation on all $15-80$ years old patients with trauma in Poursina Hospital of Guilan Province from 2015 to 2017 and reported that $70 \%$ of all the patients with spinal fractures were male and $30 \%$ were female. In addition, the mean age of patients with spinal fractures was 40.2 . Lumbar (47.64\%), cervical (30.58\%) thoracic $(21.76 \%)$ spine fractures were found to be the most prevalent.
An Icelandic retrospective study assessed hospital admissions owing to traumatic spinal fracture during a 5-year period [15]. The authors reported a total of 487 patients were diagnosed with a spinal fracture in which the mean age was 56 years Of these patients $9 \%$ developed SCl. A Spanish observational study on 282 traumatic $\mathrm{SCl}$ patients in the Canary Islands between 2001 and 2015 showed that $80.1 \%$ of the patients were males [16]. Additionally, the most frequently affected level was the cervical spine (50.9\%), and incomplete tetraplegia (29.8\%) was the most prevalent group.

\section{Conclusion}

The most telling reiteration is that men mostly had spine trauma. Lumbar region was the most susceptible place of $\mathrm{SCl}$. Moreover, most of the patients experienced score $E$ (normal neurological defects) according to ASIA.

\section{Ethical Considerations}

Compliance with ethical guidelines

The study was approved by institutional ethics committee (Code: IR.GUMS.REC.1397.517).

Funding

This research did not receive any specific grant from funding agencies in the public, commercial, or not-forprofit sectors.

\section{Authors contributions}

Sasan Andalib and Zahra Mohtasham Amiri (co-first authors) contributed equally to the paper. All authors met ICMJE criteria. 


\section{Conflict of interest}

\section{Authors declare no conflict of interest.}

\section{Acknowledgements}

We thank Guilan Road Trauma Research Center for the support provided.

\section{References}

[1] Ball PA. Critical care of spinal cord injury. Spine. 2001; 26(Supp .24):S27-30. [DOI:10.1097/00007632-200112151-00006] [PMID]

[2] Ge L, Arul K, Ikpeze T, Baldwin A, Nickels JL, Mesfin A. Traumatic and nontraumatic spinal cord injuries. World Neurosurgery. 2018 111:e142-8. [DOI:10.1016/j.wneu.2017.12.008] [PMID]

[3] Emamhadi M, Soltani B, Yousefzadeh-Chabok S, Babaee P, Behzadnia $\mathrm{H}$, Ghadarjani $\mathrm{S}$, et al. Evaluation of mesenchymal stem cells and granulocyte colony stimulating factor in treatment of complete spinal cord injury. Journal of Experimental and Clinical NeuroSciences. 2018; 5(1):1-5

[4] Ahuja CS, Nori S, Tetreault L, Wilson J, Kwon B, Harrop J, et al. Traumatic spinal cord injury-repair and regeneration. Neurosurgery. 2017; 80(3S):S9-22. [DOI:10.1093/neuros/nyw080] [PMID]

[5] Chen Y, He Y, DeVivo MJ. Changing demographics and injury profile of new traumatic spinal cord injuries in the United States, 1972-2014. Archives of Physical Medicine and Rehabilitation. 2016 97(10):1610-9. [DOI:10.1016/j.apmr.2016.03.017] [PMID]

[6] Lenehan B, Street J, Kwon BK, Noonan V, Zhang H, Fisher CG, et al. The epidemiology of traumatic spinal cord injury in British Columbia, Canada. Spine. 2012; 37(4):321-9. [DOI:10.1097/ BRS.0b013e31822e5ff8] [PMID]

[7] Van den Berg ME, Castellote JM, Mahillo-Fernandez I, de Pedro-Cuesta J. Incidence of spinal cord injury worldwide: A systematic review. Neuroepidemiology. 2010; 34(3):184-92. [DOI:10.1159/000279335] [PMID]

[8] Krause JS, Sternberg M, Lottes S, Maides J. Mortality after spinal cord injury: An 11-year prospective study. Archives of Physical Medicine and Rehabilitation. 1997; 78(8):815-21. [DOI:10.1016/S00039993(97)90193-3

[9] Ahuja CS, Wilson JR, Nori S, Kotter MRN, Druschel C, Curt A, et al. Traumatic spinal cord injury. Nature Reviews Disease Primers. 2017; 3:17018. [DOI:10.1038/nrdp.2017.18] [PMID]

[10] Kirshblum SC, Burns SP, Biering-Sorensen F, Donovan W, Graves $\mathrm{DE}$, Jha $\mathrm{A}$, et al. International standards for neurological classification of spinal cord injury (Revised 2011). The Journal of Spinal Cord Medicine. 2011; 34(6):535-46. [DOI:10.1179/20457721 1X13207446293695]

[11] Haefeli M, Elfering A. Pain assessment. European Spine Journal. 2006; 15(Suppl. 1):S17-24. [DOI:10.1007/s00586-005-1044-x] [PMID] [PMCID]
[12] Safaei M, Dehnadi Moghadam A, Yousef zade S, Kamali G. Spinal fractures in admitted patients in Poursina hospital. Journal of Guilan University of Medical Sciences. 2008; 17(66):38-43.

[13] Yousefzadeh-Chabok S, Behzadnia H, Kouchakinejad-Eramsadati L, Hosseinpour M, Alijani B, Taghinejadi O. Incidence of spinal cord injury in traumatic patients admitted to a trauma referral center in Guilan. Iranian Journal of Neurosurgery. 2015; 1(1):39-42. [DOI:10.18869/acadpub.irjns.1.1.39]

[14] Ramezani S, Mohtasham-Amiri Z, Kouchakinejad-Eramsadati L, shokatjalil $\mathrm{H}$, Yousefzadeh-Chabok S. Epidemiology of traumatic spinal fractures and spinal cord injuries in Guilan, north of Iran. Caspian Journal of Health Research. 2019; 4(1):12-5. [DOI:10.29252/ cjhr.4.1.12]

[15] Kristinsdóttir EA, Knútsdóttir S, Sigvaldason K, Jónsson H Jr, Ingvarsson PE. Epidemiology of spinal fractures and associated spinal cord injuries in Iceland. Spinal Cord Series and Cases. 2018; 4:74. [DOI:10.1038/s41394-018-0112-5] [PMID] [PMCID]

[16] Bárbara-Bataller E, Méndez-Suárez JL, Alemán-Sánchez C, Sá nchez-Enríquez J, Sosa-Henríquez M. Change in the profile of traumatic spinal cord injury over 15 years in Spain. Scandinavian Journal of Trauma, Resuscitation and Emergency Medicine. 2018; 26(1):27. [DOI:10.1186/s13049-018-0491-4] [PMID] [PMCID] 